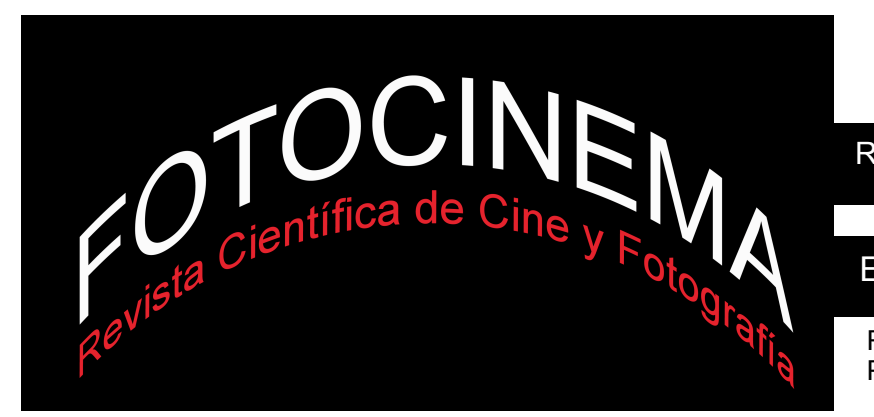

\title{
LITERATURA, CINE, VIDEOJUEGO Y CÓMIC: LA TRANSMEDIALIDAD EN THE WARRIORS
}

\section{LITERATURE, CINEMA, VIDEO GAME AND COMIC: THE TRANSMEDIALITY IN THE WARRIORS}

\author{
Juan Luis Lorenzo Otero \\ Universidade de Santiago de Compostela, España \\ juanluis.lorenzo@rai.usc.es
}

\section{Resumen:}

En la sociedad actual, el concepto de transmedialidad propuesto por Henry Jenkins es una constante en cualquier medio narrativo, creando una comunicación persistente entre soportes y ampliando la inmersión en los mundos de ficción que proponen. En esta tesitura sobresale la aparición del videojuego y su posibilidad de aumentar la inmersión en los mundos propuestos en el propio y diferentes soportes, permitiendo una mayor profundización en la obra narrativa. Este artículo tiene por objetivo analizar los procesos de transmedialidad e intermedialidad presentes en el videojuego The Warriors (2005), de la compañía Rockstar Games, y como en él se presenta y expande el universo desarrollado por Sol Yurik en su novela homónima en 1965 y plasmada en imágenes por la adaptación cinematográfica dirigida por Walter Hill en 1979, sin olvidarse de su continuación en viñetas publicada por Dymanite Comics en 2012. Con ello se pretende observar como el medio videolúdico se presenta como un elemento vehicular que ayuda a organizar una experiencia intermedial claramente contemporánea, a la vez que intensifica la inmersión narrativa en ese mundo ficticio.

\begin{abstract}
:
In today's society, Henry Jenkin's transmediality concept is regular in the narrative media, making a constant comunication betwen supports and extending inmersion in the proposed fictional worlds. In this situation the video game's appearance and its ability to increase immersion in the proposed world in different media, allowing greater deph in the narrative work. This article focuses on analyze the process of transmediality and present intermediality in the Rockstar Game's video game The Warriors (2005), and as it is presented and expands the universe developed by Sol Yurik in his novel in 1965 and the film adaptation directed by Walter Hill in 1979, and its continuation in comick-book published by Dymanite Comics in 2012. This is to see how the videogame medium is presented as a vehicle element that helps organize a clearly contemporary intermedia experience, while it is intensifying the narrative immersion in this fictional world.
\end{abstract}

Palabras clave: intermedialidad; transmedialidad; videojuego; cine; literatura; cómic.

Keywords: Intermediality; transmediality; Video Game; Cinema; Literature; Comic. 


\section{Introducción}

En la sociedad actual, el concepto de transmedialidad propuesto por Henry Jenkins es una constante en cualquier soporte narrativo. Hoy en día las diferentes formas narrativas se comunican constantemente ensanchando la inmersión en los mundos de ficción que proponen, a través de una fórmula donde «lo esencial es que en la obra exista una intertextualidad radical» (Jenkins en Scolari, 2013, p. 34). No es extraño, por ello, que beban unos de otros con el fin de expandir la realidad ficticia de sus autores, desarrollando de esta manera las experiencias del usuario, lector o espectador gracias a su presencia en diferentes soportes, técnicas y lenguajes narrativos. En esta tesitura sobresale la aparición del videojuego y su posibilidad de aumentar la inmersión en el mundo propuesto en el propio o en diferentes medios. La capacidad de interactuar con el entorno permite un mayor conocimiento del mundo narrativo proyectado, y ayuda a una mayor profundización en la obra narrativa. Este artículo intenta describir, demostrar y analizar el proceso de transmedialidad e intermedialidad presente en el videojuego The Warriors (2005), de la compañía Rockstar Games, por tratarse de una obra reconocida por su valía artística, y por ser considerado una de las mejores adaptaciones transmediales al ámbito videolúdico. Para una mejor comprensión de la temática de esta serie, se procederá a explicar como en él se presenta y expande el universo desarrollado por Sol Yurick en su novela homónima en 1965 y plasmada en imágenes por la adaptación cinematográfica dirigida por Walter Hill en 1979, sin tampoco olvidar su continuación en viñetas publicada por la editorial Dynamite Comics en 2012. En esta contribución, tras una breve descripción teórica de los conceptos de intertextualidad, intermedialiadad y transmedialidad, se analizará la traslación y aplicación práctica de dichos conceptos a la franquicia The Warriors, con el fin de prestar atención a su migración transmedia desde el medio literario al soporte videolúdico pasando, a su vez, por el cinematográfico y comicográfico. Con ello, se pretende observar como el medio videolúdico se convierte en un elemento vehicular que ayuda a organizar una experiencia intermedial claramente contemporánea, a la vez que intensifica la inmersión narrativa en ese mundo ficticio. 


\section{La intermedialidad $y$ la transmedialidad en la narrativa contemporánea}

En la actualidad los conceptos de intermedialidad y transmedialidad son una constante en las narrativas contemporáneas. En primer lugar, cabe destacar el propio concepto de medio. Este concepto está claramente ligado a la nueva sociedad de masas fruto de la edad contemporánea. El proceso industrializador surgido desde el siglo XIX habría preparado las condiciones propicias para el desarrollo de la comunicación de masas, dando lugar a una forma de sociedad donde se depende en gran medida de las citadas comunicaciones. El medio será el principal soporte de comunicación social donde las modernas industrias culturales interactúan (Gubern, 1997, p. 21). Con la sociología de masas surgen las primeras preocupaciones sobre las transformaciones que los denominados media electrónicos desarrollarían en la sociedad y cultura donde se inscriben. Por ello los canales de comunicación pueden ser interpretados como una forma de exteriorizar un pensamiento concreto, un mensaje, que podría distribuirse a través de distintos soportes -también llamados medios- y aumentar su influencia gracias al atractivo de los mismos. Esta realidad enfatiza que según el propio medio que se use, el mensaje será más o menos atractivo para los distintos estratos de la sociedad (Sánchez Jiménez, 1994, p. 10).

La presencia de distintos soportes de comunicación permite que surja el denominado proceso de intermedialidad, convirtiéndolo en una forma de interrelación entre los distintos canales o instrumentos de comunicación. La intermedialidad se entendería como la integración de uno o varios medios en otra forma o canal de comunicación. Se convertiría de esta manera en una compleja construcción comunicativa que llevaría implícitas formas de codificar la experiencia humana con los distintos procesos culturales de dichas experiencias (López-Varela Azcárate, 2011, p. 107). El concepto de intermedialidad ha dado fruto a distintos debates desde su nacimiento, y todavía no hay una definición clara al respecto. Por esta razón es muy interesante la recopilación que hace López-Varela Azcárate acerca de su génesis y su relación con el propio medio, y donde establece dos tendencias claramente diferenciadas en el estudio del proceso intermedial. En primer lugar, existiría 
una orientación derivada de los estudios literarios y narrativos, que establecería el proceso intermedial y que se centraría en el concepto de intertextualidad ${ }^{1}$. Por otro lado estarían los estudios de comunicación, que se interesarían en las distinciones materiales entre los medios y sus fenómenos asociados (LópezVarela Azcárate, 2011, p. 107-108). Ambas formas de estudio deben ser complementarias y deben relacionarse para comprender el fenómeno de la intermedialidad. De esta forma queda claro que la intertextualidad establecería la forma en que los diversos textos narrativos se relacionan entre sí, mientras que la intermedialidad sería la forma como se plasman dichas comunicaciones entre distintos canales o soportes. Por ello, la intertextualidad establecería una apertura de un diálogo entre un soporte de comunicación concreto con otras artes y modos de expresión (Martínez Fabre, 2013, p. 14).

La consecuencia lógica de este diálogo, de esta ampliación del significado, sería la posibilidad de una narración multiplataforma. Fruto de ello aparece el concepto de transmedialidad ${ }^{2}$. Este término desarrollado por Henry Jenkins, establece que una narración puede ser presentada en distintos medios de una forma en que cada uno de los mismos complemente y amplíe nueva información para el destinatario de dicha narración. Con ello se busca crear una experiencia de entretenimiento más intensa y enriquecedora, estableciendo una relación complementaria entre los distintos soportes artísticos y narrativos que amplían la significación de los mismos. La situación ideal de este concepto se daría cuando cada soporte narrativo realizara una contribución exclusiva al desarrollo de la historia o narración (Jenkins, 2003).

Al tratar una experiencia transmedial hay que hacer hincapié en la separación entre la transmedialidad y las adaptaciones o transposiciones de un medio a otro. El transmedia story-telling sería un contenido ficcional que se desarrollaría y evolucionaría en múltiples soportes y plataformas. Aunque existen numerosos estudios que analizan este concepto en ámbitos como el periodístico y otros aspectos sociales contemporáneos (para ello véanse los

\footnotetext{
1. El término intertextualidad fue acuñado por Julia Kristeva en 1969 y haría referencia a la 2. Al hablar de transmedialidad también habría que hacer referencia al concepto de transtextualidad definido por Gérard Genette en 1982, donde establecería que las relaciones intertextuales estarían restringidas a la referencia explícita y/o literal de un texto a un texto anterior. Según Genette, la intertextualidad sería una modalidad o tipo de transtextualidad.
} 
estudios de Mora y de Carrera Álvarez et al.), para este artículo se ha aplicado una definición que se centra en el ámbito narratológico: «Un proceso narrativo no lineal que se despliega a través de múltiples formatos y plataformas a partir de una historia o modo de relato que denominaremos central o desencadenante» (Carrera Álvarez et al., 2013, p. 542-543).

La narrativa transmedial se asentaría en la interrelación de fenómenos intertextuales e intermediales que se desarrollan en una narración que puede darse en cualquier soporte y que aumenta el contenido e información de la misma gracias a la inclusión de elementos únicos en cada soporte mediático.

\section{La transmedialidad en The Warriors}

Como se ha indicado, el desarrollo de la sociedad contemporánea ha permitido la aparición de una serie de nuevos soportes narrativos que han provocado una línea de reflexión de la que surgieron los conceptos de intermedialidad y transmedialidad sobre los que versa este estudio. Uno de los principales agentes de este nuevo modelo de narrativa transmedial es el videojuego, una manifestación cultural y artística que se ha situado en una posición hegemónica en el ámbito de las industrias culturales desde el comienzo del siglo XXI. La propia naturaleza del videojuego lo ha convertido en uno de los soportes por antonomasia de la narración transmedial gracias a su enorme posibilidad de interactuación. Esta innovación técnica ha permitido que el usuario pueda relacionarse con la historia de una forma distinta a las tradicionales. Hasta la llegada del soporte videolúdico, las narraciones se entendían como una relación entre el autor y el receptor de una manera contemplativa. Tradicionalmente, el autor proponía una narración, una historia, y el receptor de la misma tenía una forma pasiva de acercarse a ella. Con la llegada de la narración videolúdica la situación cambia, el receptor de la obra puede interactuar con la misma, pararse en las acciones que más le puedan interesar, explorar el mundo ficticio que se le propone o tomar decisiones conforme a como quiere que se le cuente la propia narración gracias a la elección libre -aunque esta libertad no es total ya que la historia completa está previamente planteada por el propio autor de la obra-. 
Gracias a la interactividad se aumenta la capacidad del usuario para influir en los textos e imágenes que le son presentados previamente (Cid \& Segado, 2011, p. 219). Además esta forma de narración permite que cada usuario posea una experiencia personal e intransferible, que lo convierte, en cierta medida, en creador de la estructura del relato:

En el videojuego, el usuario, no es sólo el receptor del relato sino un agente que forma parte del mismo, ya sea siendo un personaje o co-autor del mismo a través de sus propias decisiones. Gracias a ello se rompe con la estructura espaciotemporal del relato clásico, permitiendo una narración no lineal. Por ello su sistema narratológico, es un hiperrelato donde son posibles múltiples narraciones según las decisiones del usuario o jugador (Cid \& Segado, 2011, p. 223).

El videojuego se convierte en un vehículo, gracias a su particular idiosincrasia, que permite una experiencia inmersiva en una narración multiplataforma. El caso de la experiencia transmedial del videojuego The Warriors (Rockstar Games, 2005) es un ejemplo significativo de todas estas cuestiones. En un primer lugar hay que explicar que esta saga multiplataforma se inicia con la aparición de la novela homónima de Sol Yurick en 1965. La narración se basa en el relato clásico Anábasis o la Expedición de los diez mil, escrita por Jenofonte de Atenas en el siglo IV a.C., y que se centra en la odisea que los protagonistas del mismo deben superar para volver a su hogar tras haber participado en un conflicto bélico. La Anábasis explicaría la operación militar de Ciro el Joven contra el rey de Persia, su hermano Artajerjes II, y el posterior retorno de los mercenarios griegos a su servicio -entre los que se encontraba el autor de la obra, Jenofonte- a su patria tras la derrota y fallecimiento del mismo Ciro. La narración se presenta en tercera persona y con un estilo ameno y sencillo, con el que se narra un relato de corte histórico que explica las desventuras de los mercenarios en su camino de vuelta al hogar. A la hora de analizar esta obra desde una perspectiva intermedial o intertextual, no cabe duda de que este sería el punto de partida, el texto de referencia que constituirá la base para la futura experiencia transmedial de The Warriors. 
Como se ha indicado, la novela de Sol Yurick se encarga de realizar una adaptación del clásico griego, pero acomodado a su sociedad y contexto cultural. De esta forma, se presenta un relato que se adentra en la cultura de las bandas juveniles de la década de 1960 en los suburbios de la ciudad de Nueva York, acercándose de forma muy directa a los problemas de su propia sociedad y a la forma en que los jóvenes se enfrentan a cuestiones como la sexualidad, la familia o la reputación social. La narración se inscribe en la forma de un diario, donde cada capítulo se centra en un marco horario específico que se encuadra cronológicamente entre los días cuatro y cinco de julio. Además, cada capítulo se asienta en los hechos acontecidos en un margen de horas concretas y narrado en tercera persona con un fuerte sustrato de crónica3 ${ }^{3}$ La novela explica el viaje de los jóvenes pertenecientes a la banda de los Coney Island Dominators -que se caracterizan por ser una agrupación multirracial donde predominan los afroamericanos y los hispanos-, hasta la gran reunión de bandas en el barrio del Bronx, y su posterior aventura de regreso a su hogar. El relato muestra las conductas de las tribus urbanas y los jóvenes marginales de la ciudad de Nueva York -todos ellos en un margen de edad entre los 14 y los 20 años- de mediados de la década de 1960, centrándose en la forma en que se acercan a la sexualidad, la familia y las posibilidades de supervivencia en una sociedad que no se corresponde con ellos mismos. En este contexto, la novela de Sol Yurick se proyecta como una experiencia intertextual clara, donde el autor de The Warriors se ve claramente influido por el texto clásico de Jenofonte para su propia narración. Es interesante observar la presencia de un metalenguaje que relaciona intertextualmente ambos relatos, gracias a que el miembro más joven de los protagonistas lea una versión en cómic del clásico de Jenofonte. El relato clásico y el contemporáneo se relacionan en su fondo narrativo, pero a la vez, gracias a este tipo de elementos metalingüísticos, también en el propio relato escrito. En esta relación entre textos se presenta el germen de lo que será la

\footnotetext{
3. Se considera una crónica el relato literario que se sustenta en la recopilación de hechos históricos o importantes narrados en un orden cronológico. La crónica se narra según el orden temporal de los hechos acontecidos, por medio de testigos presenciales o contemporáneos, y puede ser en primera o tercera persona.
} 
experiencia transmedial e intermedial surgida a través de los posteriores filme, videojuego y cómic.

Una vez vista la relación intertextual que surge entre la obra de Jenofonte y la novela de Yurick, conviene acercarse a la experiencia intermedial que brota de su adaptación fílmica. Los amos de la noche (The Warriors, Walter Hill, 1979) presenta el mismo argumento que la novela, pero adaptada a las nuevas realidades sociales que surgieron entre mediados de la década de 1960 y finales de la década de 1970. La narración fílmica muestra una presencia de un ritmo vertiginoso, que consolida la idea de la huída que sirve de premisa fundamental de la historia. Este hecho se ve afianzado por su uso de una fotografía que impregna de oscuridad a todo el filme al crear una atmósfera de incertidumbre y tensión a través de la filmación en exteriores nocturnos y poco iluminados de la ciudad de Nueva York. La sensación permanente de oscuridad, de una ciudad nocturna y solitaria, se apuntala por medio de la figura de unas estaciones de metro vacías y parques solitarios por donde los protagonistas transitan en una constante sensación de peligro. En el plano de la actuación, el uso de actores poco conocidos ayuda a reflejar una imagen heterogénea del grupo humano protagonista, y enseña la propia diversidad de la ciudad. Es destacable la referencia al texto fuente en una secuencia introductoria muy original de unos siete minutos donde se ven pequeñas escenas introductorias - a modo de flashbacks- de los personajes, bandas y del recorrido del metro, donde se presta atención a la distancia que los "héroes" deben recorrer, sus motivaciones personales y dudas respecto a lo que les sucederá.

Es en este punto donde surge la intermedialidad en la película, gracias a la relación que se crea al conectar el lenguaje cinematográfico con el literario. De esta forma, se establecen una serie de características necesarias para su perfecta adecuación con el lenguaje del nuevo soporte a donde se transmite la historia. Aunque, como se ha indicado, el argumento del filme sería el mismo que el de la novela, aparecen claras diferencias entre ambos medios: en primer lugar, el nombre de la banda, en este caso la película presenta a los protagonistas como los Warriors mientras que en la novela eran conocidos como los "Coney Island Dominators"; en segundo lugar, existe un claro referente intermedial al medio 
del cómic en la estética de los protagonistas, al ofrecer una imagen fuertemente caricaturizada e hiperbolizada, dando lugar a una presencia estética única con la aparición de uniformes estereotipados -como si fueran disfraces- para cada banda que aparezca en el filme; en tercer lugar, hay que incidir en la diferencia de edad entre los protagonistas de la versión escrita y la cinematográfica, debido a que el relato de Yurick presenta a unos jóvenes que oscilan entre los 14 y los 20 años, mientras que su plasmación en imágenes por parte de Walter Hill muestra como todos los miembros de las bandas superan la barrera de la veintena con claridad; en último lugar, hay que resaltar el sustrato social de la novela, que se presenta, en gran medida, ausente en muchos aspectos del filme -y sólo mostrado en los barrios donde transcurre la acción-. Con todo ello, la presencia intertextual entre ambas obras -gracias a la relación clara entre el texto literario y el desarrollo del guión fílmico- y la intermedialidad -a través de la conexión que se realiza al conectar los lenguajes de ambos soportes a través de una misma historia- es evidente y fundamental para la posterior presencia transmedial. Una herramienta transmedial esencial que se observa en la narración fílmica es la adaptación del género de la crónica al soporte cinematográfico, realizado a través de pequeñas conversaciones que se dan entre los principales antagonistas y donde se narra a los mismos los actos y hechos que previamente se han desarrollado en imágenes. Este sustrato periodístico es un elemento que muestra la constante intertextual e intermedial entre el filme y sus escritos referenciales, a través de la adaptación de elementos lingüísticos claros -como podría ser la crónica de una noticia- a elementos propios del lenguaje de destino -en este caso una conversación entre personajes que traspasa la información de dicha crónica- y que a su vez refiere al género literario que corresponde el elemento intertextual en el que se inspira. De esta forma, se puede hablar de la figura de un metalenguaje que se sustenta dentro de la intermedialidad de la propia película y cuyo mejor exponente sería la presencia del soporte radiofónico en la misma. La radio se observa como una pieza fundamental de la intermedialidad en la versión cinematográfica de la historia a través de la plasmación de la misma en imágenes.4 Para ello se

4. Aunque ya tenía una gran importancia en la novela, ya que la radio se planteaba como el 
traduce el aspecto lingüístico fundamental de la radio como soporte, la voz, al propio lenguaje fílmico a través de la imagen de la boca de una mujer frente a un micrófono relatando las últimas noticias acontecidas sobre las vicisitudes de los protagonistas del filme. Se constata, así, que el trasvase de lenguajes de distintos soportes, sean artísticos o comunicativos, a otro concreto produce el fenómeno de la intermedialidad.

Una vez visto el proceso intertextual surgido entre la obra de Jenofonte y la de Sol Yurick, y la realidad intermedial que existe entre esta última y la película homónima de Walter Hill, debe revisarse el fenómeno que surge con la adaptación videolúdica. En primer lugar, hay que destacar que el videojuego The Warriors se presenta como un beat'em up al que se le añaden características propias del género sandbox 6 . La unión de ambos elementos narrativos estructurales permite que el usuario del videojuego pueda tomar decisiones sobre la forma de acercarse a la historia narrada que se le está ofreciendo y la posibilidad de explorar el mundo ficticio que se le propone, con la consecuente mayor inmersión en el mismo y sin tener que seguir un esquema estricto previamente establecido. Otra novedad consustancial a la adaptación videolúdica es la posibilidad de operar por los barrios y localizaciones donde se sustenta la acción narrativa, permitiendo que el usuario -el receptor de la obrapueda observar, analizar y moverse con libertad por las localizaciones de la ciudad de Nueva York donde se sitúa la narración ficticia de la saga.

Es evidente, que al igual que ocurría con la relación entre novela y filme, existen varias referencias intertextuales e intermediales dentro del propio videojuego. Es importante detectarlas antes de adentrarse en la realidad transmedial que,

medio que tenían las bandas juveniles de comunicarse entre ellas a través de la emisión de canciones que significaban cuestiones y acciones concretas. Esta realidad también se observa en el propio film, debido al uso de las canciones que se emiten desde la radio y al significado concreto para los destinatarios de las mismas -un ejemplo sería el momento en que la locutora de radio presenta Nowhere to Run, de Martha and the Vandellas como referencia a que los protagonistas del film, los Warriors, no podrían huir de sus acciones-.

5. Conocido popularmente como "yo contra todo el barrio", se trata de un género videolúdico en el que el protagonista -o grupo de protagonistas- combaten cuerpo a cuerpo contra un gran número de antagonistas.

6. Género videolúdico no lineal, donde el orden de las acciones del jugador no está previamente establecido. Esto no impide que puedan existir una serie de objetivos que guíen al jugador, quien puede optar por obviarlos. Ofrece al jugador la posibilidad de moverse con libertad por un mundo virtual y alterar cualquier elemento del mismo. 
también, existe en el videojuego. La intertextualidad se aprecia a través del uso de la trama y los personajes de la película homónima de Walter Hill, quienes son la base original sobre la que se enmarca el conjunto del videojuego. La historia principal, la narración base sobre la que se asienta todo el videojuego, será una conexión argumental entre los textos originarios -en este caso la novela de Sol Yurick y el filme de Walter Hill- y el texto videolúdico de Rockstar Games, que también posee una estructura narrativa en forma de diario. La faceta de intermedialidad también se encuentra presente en el videojuego por medio de las herramientas formales que los desarrolladores utilizaron para mostrar los diferentes intercambios entre soportes. Un ejemplo claro de esto último sería el uso de la captación de movimientos y facial para crear una mayor coherencia entre ambos medios, o el uso de planos de cámara fija para narrar secuencias de persecución del mismo modo que se podían observar en la propia película. Otro ejemplo sería el uso de las voces originales de los actores del filme para dar vida a sus homónimos virtuales, o el uso de la misma banda sonora para cohesionar las realidades de la interactuación entre los distintos medios. Otra presencia intermedial clara sería la presentación de los personajes y bandas callejeras, con una estética fuertemente caricaturizada y con un plano fijo en una base bicromada a modo de viñeta de cómic. Esta realidad intermedial desarrolla una forma de introducción al espectador en la que podría ser una experiencia transmedial que «más bien invitan al fetichismo que, en su mismo homenaje, proporciona a los amantes del género la inmersión en vivo (interactiva) en sus historias» (Martínez Fabre, 2013, p. 17).

Con ello, se observa como los elementos intertextuales e intermediales configuran una realidad que, gracias al soporte interactivo del videojuego, puede desarrollar una experiencia transmedial inmersiva. El videojuego de Rockstar Games propone al usuario una adaptación de los textos fuente a través de los 24 capítulos que presenta, pero donde sólo cinco de ellos narran lo acontecido en el filme y en la novela. El resto se encarga de aumentar la información sobre el trasfondo de los personajes, su sociedad, su cultura y su modo de vida, creando una historia nueva que amplia la significación de la obra original y presenta novedades narrativas. Esta reflexión permite prestar 
atención a como se cumple la definición que del fenómeno transmedial realiza el investigador Henry Jenkins:

Transmedia storytelling represents a process where integral elements of a fiction get dispersed systematically across multiple delivery channels for the purpose of creating a united and coordinated entertainment experience. Ideally, each medium makes it own unique contribution to the unfolding of the Story (Jenkins, 2011).

Argumentalmente, el videojuego comienza presentando la reunión de bandas desencadenante de las acciones de la novela y la película, con lo que se establece una relación directa intermedial, pero rápidamente se traslada la narración a 3 meses antes de los sucesos acontecidos en los textos fuentes. De esta manera, el videojuego, se encarga de aportar información previa a lo acontecido en el filme. Ya se ha indicado que el videojuego usa una presentación de los capítulos a modo de diario -indicando fecha, hora y lugar donde acontecen los hechos- y con lo que se relaciona directamente con el género narrativo adoptado por la novela. A lo largo de los 18 capítulos previos a los que compondrían la narración fílmica, los desarrolladores del videojuego establecen un contexto narrativo donde explican al usuario la motivación de las bandas, el proceso de formación de la banda protagonista, sus relaciones socio-políticas con otras, y la realidad social donde se inscriben sus acciones. Además, ofrece un espacio y tiempo específico para mostrar quienes son, la forma de comportarse y las motivaciones personales de cada uno de los nueve pandilleros protagonistas de la película, aumentando de esta manera el desarrollo de los personajes -ya que en su mayoría aparecían claramente desdibujados en el filme-. La interactividad propia del medio videolúdico permite la posibilidad de explorar el territorio de los Warriors y elegir la forma de narración que cada uno prefiera, otorgando una libertad que permite elegir entre usar una narración lineal $\mathrm{u}$ otra transversal llena de flashbacks y saltos narrativos.

Otra realidad transmedial se puede detectar en la adaptación de los capítulos que relatan los hechos acontecidos en la película. Al tratarse de una adaptación textual de un lenguaje específico a otro concreto -en este caso del fílmico al videolúdico-, deben hacerse modificaciones que favorezcan dicho trasvase. En 
este caso se opta por aplicar una realidad transmedia que ayuda a ampliar las secuencias fílmicas -ejemplos de ello serían la extensión de las persecuciones que se dan en el filme mostrando como los protagonistas intentan despistar a sus adversarios, la necesidad de ser sigilosos y ocultarse para pasar desapercibidos en territorio enemigo, o el típico enfrentamiento contra el líder de cada banda para demostrar la superación de la fase o capítulo correspondiente7-. De esta forma, la transmedialidad no está contemplada sólo con la narración de hechos acontecidos antes de la película o la novela, también se ve gracias a la mencionada ampliación de los hechos propios de la película con un consecuente aumento de la significación de la misma. Como punto final, esta reafirmación de la transmedialidad presente en el videojuego también puede confirmarse ante la posibilidad de continuar realizando acciones diversas -pequeñas aventuras dentro del territorio de los Warriors, misiones secundarias centradas en una competición agonal dentro del propio juego, historias no conducentes a la narración fílmica,...- que permiten la continuación de las acciones del usuario incluso cuando la conclusión de la narración original ha tenido lugar. Este dato, además, se asienta en una realidad de coherencia del relato, ya que los personajes que han sucumbido a lo largo de la historia narrada -sea que hayan muerto, hayan sido arrestados o se encuentren desaparecidosno están presentes entre el resto de compañeros tras el final de la historia base. El videojuego The Warriors se presenta como una práctica transmedial que explota, aumenta y configura una experiencia completa e inmersiva dentro de un universo ficcional que explora más allá del texto fuente y permite una sensación personalizada y única de acercamiento a la misma.

Aunque la experiencia transmedial que presenta la obra de Rockstar Games es la más completa de la saga, no se puede obviar la inclusión del medio comicográfico $^{8}$ al conjunto de The Warriors. A través de una serie de cuatro

\footnotetext{
7. Este último es un rasgo característico del videojuego que debe aparecer como resultado de la coherencia discursiva del medio narrativo que se está usando. El género del beat'em up se basa en la superación de una fase donde el usuario se enfrenta a diversos adversarios, siendo la derrota del "jefe final" el culmen de la fase y la única fórmula de poder pasar de un capítulo a otro.

8. No se puede obviar que el cómic se ha llegado a considerar una precursor de la multimedialidad gracias a que en dicho medio se da la aparición de un lenguaje verbo-icónico (Darici, 2014, p. 303).
} 
números de comic-book ${ }^{9}$ distribuido por la editorial Dynamite Comics en 2009 y desarrollado por los autores Eric Henriksen, Herb Apron y Todd Herman, The Warriors Jailbreak presenta una continuación de los hechos narrados en la película y el videojuego. $\mathrm{Su}$ inicio se establece seis meses después del fin indicado en el texto fuente. Su forma presenta una mezcla de la realidad del futuro de los protagonistas - la nueva vida que tienen que enfrentar tras el final de la película- con reminiscencias del pasado, a través de flashbacks, que ayudan a la narración transmedial y otorgan información que en el filme no existía. Su estilo visual bebe del modelo cartoon $^{10}$, buscando caricaturizar a los personajes, pero sin dejar de ser reconocibles, con lo que se vuelve a observar la importancia de la intermedialidad en la saga gracias a la migración de la estética de los actores del film a las viñetas del cómic. A nivel narrativo el relato se centra en la vida de los supervivientes a los hechos acontecidos en la película, presentando la manera en como los mismos se enfrentan a los problemas sobrevenidos en el texto original, sus propias acciones en el mismo y sus relaciones personales. El cómic se encarga de abordar temas como la lealtad, la idea de la familia e intenta cerrar narrativamente una historia que presentaba un final claramente abierto en el filme y novela en la que se inspiran.

\section{La significación de The Warriors}

Una vez observado el fenómeno transmedial -sin obviar el intertextual y el intermedial- presente en la narración de The Warriors, debe dedicarse un momento para analizar la significación de la misma. Es importante destacar la realidad socioeconómica que muestra la propia saga en todas sus experiencias narrativas -ya sea novela, película, cómic o videojuego-, donde siempre se refleja la sociedad de las bandas juveniles de los suburbios de la ciudad de Nueva York. De esta forma, la percepción de la realidad urbana donde se

\footnotetext{
9. Cuadernillo de pocas páginas (la media suele de ser de unas 24) de pequeño formato (unos 17 x $26 \mathrm{~cm}$ ) que incluye una historia completa o el capítulo de una saga más o menos larga. El comic-book nació en estados Unidos inicialmente para recopilar tiras de prensa; posteriormente, acogió historietas originales de nuevos personajes con historias ambientadas en todo tipo de géneros.

10. Término usado para referirse a la animación norteamericana y a su estética característica.
} 
inscriben es un elemento fundamental durante toda la experiencia transmedial, su lugar de acción son los suburbios de las ciudades, los barrios menos favorecidos, donde se agrupan las principales minorías étnicas de la ciudad. Sea cual sea el medio narrativo y/o artístico que describa el relato, enseña la misma definición del grupo social: jóvenes marginales en lugares marginales. Como se indicó, la novela posee un importante sustrato social, adentrándose en la forma de actuar de los jóvenes de la década de 1960 en la ciudad neoyorquina y su acercamiento a temas como la sexualidad, la familia, el estatus social o las posibilidades de supervivencia dentro de una sociedad que se les luce adversa.

El videojuego ahonda en esta realidad social, al desplegar una ciudad de carácter postindustrial cuyos escenarios están llenos de edificios derruidos o abandonados. La sectarización social también está presente en las propias bandas marginales, cuyos miembros forman parte de las minorías de la ciudad y viviendo al margen de la sociedad. Al igual que sucedía en la novela, aparecen una gran cantidad de bandas con multitud de etnias, siendo los Warriors la que muestra una realidad más heterogénea: mientras que en la novela presentaba a afroamericanos e hispanos, en el videojuego -y también en la película- se añaden, además, hombres blancos. El resto de bandas presentan a los grandes guetos de Nueva York: las triadas y bandas juveniles en Chinatown, puertorriqueños y cubanos en los barrios hispanos, afroamericanos en el Bronx..., y todos ellos conviven en barrios que se encuentran rodeados de fabricas y almacenes abandonados. La posibilidad que ofrece el videojuego de acercarse, y detenerse, en cada escenario propuesto permite ver como los autores de la obra han buscado afianzar la sensación de marginalidad y pobreza dentro del mundo ficticio, pero que a su vez refleja una clara hipérbole de la ciudad y la sociedad real en la que se inspira.

La sociología se ha acercado al fenómeno urbano de los barrios marginales y los guetos de las ciudades americanas. Mike Davis plantea, en un estudio sobre la ciudad de Los Ángeles, una serie de cuestiones que podrían ser perfectamente extrapolables a la ciudad de Nueva York que se presenta en la experiencia transmedial de The Warriors. Davis incide en que la polarización social fruto del proceso postindustrializador surgido a partir de mediados de la década de 
1970 provoca un apartheid espacial entre las minorías y los grupos sociales desfavorecidos con respecto al resto de la sociedad. La creciente recesión, la huída de las grandes corporaciones o los grandes recortes de presupuesto, serían algunos de los motivos de esta exclusión social (Davis, 2001, p. 6). La novela de Yurick exterioriza de forma clara estos factores, mientras que el filme apenas lo esboza en sus imágenes y el videojuego lo exhibe visualmente -tanto en la imagen de transeúntes, proliferación de mendigos o la presencia de unas instalaciones urbanas en claro abandono-, que provocan que los jóvenes marginales se vean obligados a buscar una salida a su situación que los conduce a la delincuencia. En palabras de Davis: «cuando los distritos residenciales mejores van retrocediendo ante el empuje de los negocios y la industria, las bandas se desarrollan como una manifestación más de la frontera económica, moral y cultural que marca el intersticio» (Davis, 2001, p. 11-12).

Esta desigualdad social se plasma también en la conducta violenta observada en la película, la novela, el videojuego y el cómic. En una sociedad donde no existe la posibilidad de migrar a un estatus superior donde poder vivir cómodamente, los jóvenes se ven abocados a realizar cualquier cosa para sobrevivir y escapar de una vida de miseria. La narración y presentación de las motivaciones de los diferentes personajes se adentran en el intento de escapar del lugar donde les ha tocado vivir: Cleon, Mercy, Swan o Cyrus en la película, a los que se le añadirían Fox, Cochise o Vermin en el videojuego, y Rembrandt en el cómic, muestran su voluntad de buscar una mejor vida.

Esta forma de entender el estatus social fruto del enfrentamiento armado, de la batalla entre grupos distintos, muestra la base sobre la que se asientan las conductas violentas transmitidas en esta saga transmedial. Una sociedad marginal, que no posee recursos ni posibilidades de subir en el escalafón social sólo puede competir contra otras sociedades como la suya, con el único fin de aumentar su reputación y saciar su orgullo.

Ante estas conductas violentas existe, tanto en el texto fuente de la novela de Sol Yurick, como en la experiencia transmedial del filme, el videojuego y del cómic, la posibilidad de unión, la oportunidad de salir de la miseria gracias a apoyarse en el contrario y no luchar contra él. La base narrativa de la historia surge de 
una gran reunión entre bandas -promovida por Ismael en la novela, Cyrus en su versión fílmica, videolúdica y comicográfica- cuyo fin es el cese de hostilidades, un alto el fuego que permita a los jóvenes marginales agruparse y controlar la ciudad. Es una forma de decidir su propio destino más allá de seguir en la pobreza a la que se ven abocados. La única vía para conseguir un sueño de igualdad, que se verá truncado debido a la propia segregación social presente en las bandas ya sea por su credo, ideología o color de piel, y que se refleja en esta experiencia transmedial.

\section{Conclusiones}

Ha quedado claro que el videojuego The Warriors es un ejemplo de transmedialidad, donde se aúnan la intertextualidad e intermedilidad, posibilitando que una persona en concreto pueda diseñar una narración personal e intransferible gracias a la propia peculiaridad del medio videolúdico y a su libertad de elección. Punto clave debe ser la separación entre la simple intermedialidad de un medio a otro distinto, y la transmedialidad bajo la premisa que introdujo Jenkins: la de un texto narrativo que se desarrolle en distintos soportes comunicativos complementándose entre ellos y aportando novedades de uno a otro. La forma desarrollada por Rockstar Games contribuye, sin lugar a dudas, a entender la fórmula propuesta por Jenkins, al introducir novedades narrativas incluso dentro del propio texto de referencia gracias al trasvase de soportes.

Igualmente relevante es la lectura social y simbólica que se extrae gracias a la plasmación en imágenes de un texto literario. Al haber indagado en la lectura sociológica de la novela, el aspecto visual que posee el videojuego permite al usuario adentrarse en una sociedad donde pobreza y marginalidad se observan por doquier. Los edificios en desuso, las fábricas abandonadas, los vagabundos y sin techo por la calle, el ambiente nocturno y marginal, muestran la crónica de una sociedad concreta que puede ser explorada por el usuario del medio videolúdico. Toda esta tramoya permite desplegar una ácida crítica social que haga reflexionar al que se acerque a la misma. La experiencia transmedial 
desplegada entre los propios medios artísticos -en este caso el literario, el cinematógrafo, el cómic y el videojuego- permite ver como cuestiones sociales específicas se presentan en distintas décadas con la misma mirada crítica -ya sea más o menos profunda-, configurando una forma de denuncia social que puede llegar a un público mayor que si se diera en un único medio.

Sin lugar a dudas, el videojuego se conforma como un medio artístico que puede interactuar con otros medios de carácter narrativo con el fin de aumentar la significación de los mismos. La narración ficticia transmedial se ha encontrado con una de sus herramientas fundamentales con la aparición del videojuego y su capacidad intrínseca de aunar medios artísticos y comunicativos, estableciendo una forma única de narrar y de la que The Warriors es uno de sus ejemplos más remarcables.

\section{Referencias bibliográficas}

Anyó Sayol, L. (2016). El jugador implicado: Videojuegos y narraciones. Barcelona: Laertes.

Carrera Álvarez, P.; Limón Serrano, N.; Herrero Curiel, E.; Sainz de Baranda Andujar, C. (2013). Transmedialidad y ecosistema digital. En Historia y comunicación social. Vol.18, NºEsp. Nov. pp. 535-545.

Cid, F.; Segado, F. (2011). Teoría e Historia de la imagen. Madrid: Editorial Síntesis.

Darici, K. (2014). El cómic y la transmedialidad. El caso de La Doce de François Schuiten en Realidad Aumentada. En CIC. Cuadernos de Información y Comunicación. Vol.19. pp. 303-313.

Davis, M. (2001). Más Allá de Blade Runner. Control urbano: la ecología del miedo. Barcelona: Virus Editorial/Latlevin S.L.

Garfias Frias, J. Á. (2010). La industria del videojuego a través de las consolas. En Revista mexicana de ciencias políticas y sociales. $\mathrm{N}^{\mathrm{0}} 209$. pp. 161-182.

Genette, G. (1989). Palimpsestos. La literatura en segundo grado. Madrid: Taurus.

Gubern, R. (2005). De la palabra a la tecnoescritura. En Quintana. No 4 . pp. 131136.

Gubern, R. (1997). Medios icónicos de masas. Madrid: Historia 16.

Huizinga, J. (2007). Homo ludens. Madrid: Alianza.

Jenkins, H. (2003). Transmedia Storytelling: Moving Characters from Books to Films to Video Games Can Make Them Stronger and More Compelling. Technology Review. Recuperado de https://www.technologyreview.com/s/401760/transmedia-storytelling/ 
Jenkins, H. (2011). Transmedia 202: Further Reflections. Recuperado de http://henryjenkins.org/2011/o8/defining_transmedia_further_re.html

Kristeva, J. (1981). Semiótica 1. Madrid: Editorial Fundamentos.

Leone, M. Héroes y antihéroes trans-textuales: el caso Kong2012. En CIC. Cuadernos de Información y Comunicación. Vol.19. pp. 197-214.

Levis, D. (2013). Los videojuegos, un fenómeno de masas. Buenos Aires: Sivel.

López-Varela Azcárate, A. (2011). Génesis semiótica de la intermedialidad: fundamentos cognitivos y socio-constructivistas de la comunicación. En CIC. Cuadernos de Información y Comunicación. Vol. 16. pp. 95-114.

Marigón, C. (2012). Manga, anime y videojuegos japoneses: análisis de los principales factores de su éxito global. En Puertas a la lectura. $\mathrm{N}^{0} 24$. pp. 28-43.

Martínez Fabre, M.-P. (2013). Game play abierta. Intertextualidad, intermedialidad y autorreferencia en la partida de juego. En LifePlay: Revista académica internacional sobre videojuegos. Vol.1, $\mathrm{N}^{\mathrm{o}} 1$. pp. 9-26.

Mas, R. (2008). Adiós al estigma del videojuego: Game Over. En Descubrir el Arte. $\mathrm{N}^{\mathrm{o}} 115 \cdot \mathrm{pp} \cdot 7 \mathrm{O}-75$.

Mayor Mayor, F. (2014). Transmedia Storytelling desde la ficción televisiva española: El caso de Antena 3. En CIC. Cuadernos de Información y Comunicación. Vol.19. pp. 69-85.

Montés Pérez, M. (2010). Narrativa en las aventuras gráficas. En Frame: revista de cine de la Biblioteca de la Facultad de Comunicación. Nº6. pp. 243-264.

Mora, V. L. (2014). Acercamiento al problema terminológico de la narrativa transmedia. En Caracteres: estudios culturales y críticos de la esfera digital. Vol.3, $\mathrm{N}^{\mathrm{o}} 1$. pp. 11-41.

Mott, T. (ed.) (2011). 1001 Videojuegos a los que hay que jugar antes de morir. Barcelona: Grijalbo.

Pérez Indaverea, M. A. (2012). Espacios urbanos en el videojuego: París como escenario de tensión. En Ángulo Recto. Revista de estudios sobre la ciudad como espacio plural. Vol.4, $\mathrm{N}^{\mathrm{O}} 1$. pp. 31-48.

Pérez Latorre, Ó. (2012). El lenguaje videolúdico: análisis de la significación del videojuego. Barcelona: Laertes.

Sánchez Jiménez, J. (1994). Los mass media. En Cuadernos del Mundo Actual, Vol. 42. pp. 5-31.

Scolari, C. (2013). Narrativas transmedia. Cuando todos los medios cuentan. Barcelona: Deusto.

Cómo citar: Lorenzo Otero, J. L. (2017). Literatura, cine, videojuego y cómic: la transmedialidad en The Warriors. Fotocinema. Revista científica de cine $y$ fotografía, $\mathrm{n}^{\mathrm{o}}$ 14, pp. 255-273. Disponible: http://www.revistafotocinema.com/ 